\title{
Spatial Requirements for Elderly and Disabled People in the Frame of Universal Design
}

\author{
Yavuz Arat \\ Konya Necmettin Erbakan University, Turkey
}

\section{Introduction}

Human beings' need for shelter, which is one of the most natural and important needs, is dealt by designers in its simplest form. While designers design spaces in broad sense, they have to protect the demands and needs of the users. However, space, which has become standardized in terms of construction technology with industrial revolution, and its equipment's constitute the monotonous part of human life. On the other hand, at the beginning of modern architecture, architects were not only construction designers, but also furniture designers.

According to the universal design understanding, serving to the whole regardless of users' length-body differences and physical skills, is the main point. The spaces that are designed by using average values set and opposing the universal design understanding, limit elderly and disabled peoples' standards of living. Because average measure system is used in shelter units, which are primary designed spaces, the necessary physical requirements for elderly and disabled people cannot be met. Nevertheless, the concept of 'design for everyone' that is one of the general criteria of universal design, aims to provide more independent living condition for those who live outside of the physical restraints. Universal design contains such a design understanding that includes users' space and equipments from the perspective of users.

The aim of this study is to expose how to handle universal design criteria in space design for elderly and disabled people. In this scope, it is intended to look at the solutions for the space design focused problems encountered by elderly and disabled people from the perspective of "universal design" and search the solutions for the common problems in design issues. To produce this point of view, it is discussed that how the design quality desired in general design approaches should be handled in specialized building design in the scope of this study. At this point 
spatial requirements for elderly and disabled people will be evaluated systematically in the frame of universal design.

The sample area for the study is "The Research and Rehabilitation Center for Elderly - Disabled" the projects of which is still being prepared and located in Konya Selcuk University. The approach which will be developed in the scope of this study will contribute to the spatial production of this center in the quality of a composed structure including social areas with different scope and content as the design of the center is not completed yet.

The method of the study is composed of four phases. First phase includes a series of design explanations from general to special providing definitions of universal design approaches and the evolution of these approaches in architecture. In second phase the spatial requirements answering the problems of design for elderly and disabled people are evaluated. In third phase, the center is shortly introduced. In the last phase, the center is evaluated together with the data obtained in the study, and the results are explained.

In this scope when it is considered that this study explains the principal approaches which are not/cannot be applied in general design problems in detail from general to special, it is thought that the study will provide a different point of view for the accessibility focused problems in building groups designed for elderly and disabled individuals.

\section{Materials and Method}

\section{Universal Design Approach in Architecture}

The concept of 'design for everyone' in architecture includes the design of space, environment, and equipment aimed at users regardless of their age and skills. Convenience to environmental conditions as well as users' ergonomic features is described as universal design.

The quality of life in an architectural space is measured by the opportunities it offers for all of its users to use every function the space provides. The factors needed to be oversaw in spatial formations providing opportunities for all individuals to use is possible by realizing a series of precautions and design criteria allowing the identity of the user to be varied. In this user variation, to marginalize the individuals by differentiating them such as elderly-young and/or disabled unimpeded causes accessibility problems for every individual. 
It can be said that every healthy individual is a candidate to be disabled or everyone will get older and live some changes in his body and loose some abilities. At this point the quality of architectural space gains importance from the point of criteria to be considered while handling the components of it.

Along with this, the freedom of elderly and disabled people to access the areas for common use is protected by law as well as the rights of the impeded people to use these areas. In this scope, universal design principles supporting legal regulations are considerable in the point of handling the design problems in a multi-directional way. Because, when it is thought that the right to access is universal, the loss of the inclusiveness character in the buildings and spaces and inability of them to fulfill all the wills and needs of all users will cause new problems in related areas. From this point of view, it is necessary to investigate universal design principles and the aim and scope of them in detail.

Universal design appears as 1) products that do not require readjustment or special design, and are used by as much people as possible; and, 2) design of environment (Preiser and Korydon, 2011).

In architecture, it is assumed that any designed object can universally be used regardless of users' skills as long as it easily serves to all peoples' benefit, and convenient in terms of ergonomics. The aim of universal design is to design extendable environment, space and equipment, in addition to accessibility. The definition and principles of the concept, universal design, were developed by a study group called, “The Center for Universal Design" in USA's North Carolina University (Boduroğlu, Seçer Kariptaş, Sarıman Özen, 2012).

The principles of universal design was published in "The Center for Universal Design" (CUD, 1997; Preiser and Korydon, 2011).

Principle 1: Equitable Use: The design is useful and marketable to people with diverse abilities. In other words, designs should appeal to diverse populations and offer everyone a comparable and nonstigmatizing way to participate.

Principle 2: Flexibility in Use: The design accommodates a wide range of individual preferences and abilities. In other words, designs should provide for multiple ways of doing things. Adaptability is one way to make designs universally usable.

Principle 3: Simple and Intuitive Use: Use of the design is easy to understand, regardless of the user's experience, knowledge, language skills, or current concentration level. In other words, make designs work in expected ways. 
Principle 4: Perceptible Information: The design communicates necessary information to the user, regardless of ambient conditions or the user's sensory abilities. In other words, designs should provide for multiple modes of output.

Principle 5: Tolerance for Error: The design minimizes hazards and the adverse consequences of accidental or unintended actions. In other words, designs should make it difficult for users to make a mistake; but if users do, the error should not result in injury to the person or the product.

Principle 6: Low Physical Effort: The design can be used efficiently and comfortably and with a minimum of fatigue. In other words, designs should minimize strain and overexertion.

Principle 7: Size and Space for Approach and Use: Appropriate size and space is provided for approach, reach, manipulation, and use regardless of the user's body size, posture, or mobility. In other words, designs should accommodate variety in people's body sizes and ranges of motion.

In this sense, the principles of universal design were formed with the aim of integrating the features that will meet the needs of as many users as possible with design in a better way.

Universal design simply means that the houses where individuals and families live and the products they use are designed to accommodate people of all physical abilities, not just elderly or disabled persons. Incorporating these design features into the everyday living environment would make living easier for all persons in the house, both present and future (Berger, 2002; Goptop and Memken, 2005). Modifications to homes with aging individuals can be made for safety and ease of living in the home. These modifications could include installing grab bars in the bathroom, installing better lighting for diminished vision, placing handrails in strategic places, and replacing hard-to-grasp faucets and doorknobs with lever handles (Goptop and Memken, 2005). Other modifications could include gently graded walkways, height adjustable closet bars, wider doors and hallways, handheld showerheads, and cabinets with pull out shelves. These options could be added unobtrusively either during new construction or in a renovation project (Berger, 2002; Goptop and Memken, 2005).

Eventually, universal design has a completeness of principles including all design areas. From that point of view, it includes a series of criteria to be followed during the programming, designing, detailing and application processes of the buildings in the scope of integrated building having a formation which can be a model offer in architectural designs. In general meaning, it can be said that increasing the 
inclusiveness of an architectural space can be possible if it is built according to the universal design criteria. Universal design principles are preferred because of its human focused structure and the will to provide equal opportunities in forming the relationship between the space and its equipment - as encountered in every design problem. Rather than a production of a model, the method applied in the scope of the study is formed of 7 principles carrying general regulation principles wanted to be in design problems. The data obtained from these principles is comprehensively evaluated from the point of the program principles of the center as the sample area of the study.

\section{Spatial Needs of Elderly and Disabled People from the Perspective of Universal Design}

It is believed that spatial needs shape/change according to the physical capacity of elderly and disabled population as well as those people's desired lifestyles. In other words, physical capacity resources and expected lifestyles of elderly people are the basic determinants of spatial typology.

Within the framework of the abovementioned variables, spatial needs of elderly and disabled people can classified as the follows, spatial needs of independent; semi-independent; and dependent population.

\section{Spatial Needs of Elderly Population}

The classification of the following sheltering units will be delineated in terms of elderly sheltering units. It is supported that sheltering forms for disabled people should be considered according to the level of self-sufficiency, instead of disability groups; therefore, sheltering for both groups has similar characteristics.

\section{Spatial Needs of Independent Elderly Population}

The concept of independent elderly population refers to healthy -hearty- old people who can live without being dependent on any person, and take care of themselves.

The basic principle regarding the housing design for sheltering need of independent elderly population is based on the physical capacity of elderly-disabled population and their self-sufficient life style. Accordingly, houses designed for independent elderly-disabled population can be classified as, 
- Rental or residential property designed in a way that will meet the needs of elderly people,

- Elderly and disabled properties, with reference to gradually increasing elderly population and cluster housing applications of developed countries based on the needs of elderly population (Karataş 1992).

The discussion of housing options of elderly and disabled population, from this point of view (Karataş 1992, Bakker 1997, Billig 2000), housing options for elderly people can be divided as rental or sale properties; properties that are built by re-functioning; and new properties.

a) Rental or residential properties are independent houses, in which old people live and are willing to keep living throughout their elderly years that are redesigned by their occupants according to their needs and tendencies; and arranged in a way that meet all the needs of old people.

b) Houses built by re-functioning; are properties that are constructed in order to provide comfortable environments to elderly people living in neglected or outdated houses. In other words, these are houses that are formed according to the needs of elderly people, by means of functional and spatial arrangements on old and outdated properties.

c) New Properties; houses in this group are produced as a spatial result of policies that aim to evaluate and solve housing problem of elderly people within the framework of cluster housing policies, based on the increase in elderly population in developed countries especially like Germany or Britain.

The main aim of these policies is to reduce social isolation of elderly and their social bonds between generations through providing sale-rental or maintenance facilities. In this sense, housing construction or options based on the needs and tendencies of elderly people find place in the planned cluster housing areas. Analyzing elderly population-based housing options in cluster housings, it can be seen that there are two approaches in cluster housing areas, scattered and grouped housing options.

- $\quad$ Scattered Houses; refer to a model aims to integrate young population and other population groups, with elderly population by putting them together in a certain housing area.

- Grouped Houses; address to a model, in which elderly properties are designed by integrating cluster housing with socio-cultural equipment's like, 
administration, healthcare \& social services, and recreation areas. In this sense, "Village of Retiree" or "Multiplex Housing for Elderly" are solutions from European countries that can be referred as examples.

\section{Spatial Needs of Semi-dependent Elderly Population}

The concept of semi-dependent seniors refers to an elderly population group that needs professional services. However, the important point is to take into account problems stemming from traditional life style changes that take place when elderly people do not want to change the place they live, and even if they change they find the place odd.

Old people have difficulties in maintaining daily lives and meeting their needs, and they become unable to care for themselves, these facts naturally bring about the need for professional care services.

Independent life style, the desire to live independently is an important phenomenon. On the other hand, making a sacrifice in terms of independence and getting professional care-support help become obligatory as people age and start to lose their physical abilities. Therefore, different spatial preferences for dependent old people come to the fore;

- Elderly people living in their own houses or their children's houses,

- Elderly people living in houses that have professional care services,

- Elderly people living in retirement house of nursing house.

Houses of relatives of children; is considered to be a preference that provides physical and psychological support to the elderly person, social and economic support to the children. However, the negative aspect for the elderly person is that he cannot satisfy his need to be independent.

Most of the time elderly people share various responsibilities when they live with their children; yet there is always a conflict stemming from different tastes and needs. Therefore, living with the elderly is not seen as a preferred sheltering option (Karataş 1992).

Houses Supported with Professional Services; include sheltering models that are designed based on elderly people's unwillingness to leave their houses; and include 
healthcare services. The basic aim of this model is to provide long term or short term in-house health care services that elderly people need or will need.

Within the scope of this model, elderly people are cared in their house and they keep doing daily life routines. This model, which enables elderly people to live without being separated from family members and family life, is generally popular in developed countries due to investment and implementation costs (Brummet 1994, Regnier 1994).

Old people's house or nursing homes; refer to a model that provides housing units designed for old people that their psychological and social needs are met as a whole. Old people's house or nursing homes model is designed for elderly people who do not want to be isolated from society, have concerns about independent life, and need help in their personal lives (Karataş 1992).

\section{Spatial Needs of Dependent Elderly Population}

Dependent elderly is a person who needs constant care in order to survive. It is necessary to provide a full-controlled life and extensive healthcare service to dependent elderly people. For this reason, there are two different sheltering opportunities for dependent elderly people: 1) nursing house or rehabilitation centers that are supported by expert agency and institutions; or 2) elderly people's own houses.

- Nursing houses or rehabilitation centers

- Elderly people's own houses

Nursing houses; generally provide services to seniors aged between 60 and $90^{+}$. These facilities provide not only a variety of social-cultural activity opportunities, but also high quality medical services. In these centers there are opportunities for active seniors as well as fallen and disabled elderly people.

Nursing houses employ full time healthcare staff, who are ready to provide care and medical support; thus, the main aim these centers is to meet the needs of elderly people in daily life.

In this sense, there are elderly population-based functional or specialization differences in terms of functional qualities of nursing houses. Accordingly, nursing houses -as part of hospitals' elderly care unit or general health service- apart from centers providing accompaniment care that are undertaking medical support function, and medical support; can be classified as centers, in which elderly 
people's daily needs are met by a assistant health staff like nurse or caregiver, providing long term care support to elderly people (Munro 1996).

Other than abovementioned centers, there are also centers providing daily care for elderly people; these centers are elderly people oriented and do not provide service for long term care and therapy. These centers can be grouped as daily care and treatment hospitals; rest homes; and, daily care centers (Pakdil-Pakdil 1996).

Elderly people's own houses: refers to a model that elderly people, who needs constant care, are supported in their house by one or more than one health personnel, and continue living in that way. This model, is assumed to be a positive option in terms of psychological satisfaction, since it enables seniors to live in their houses; even though there are potential healthcare problems that may stem from seniors' care (Karataş 1992, Billig 2000).

Apart from the models/options that have been explained so far, there are also alternatives that enable independent, dependent and semi-dependent elderly people to live together. Within the framework of this approach that is also preferred by seniors, it was aimed that semi-dependent and dependent elderly people live together in houses that were designed for elderly population.

The attractive point of this model is that a healthy old individual, who is living in independent living conditions, has the opportunity to move to the houses that were allocated for semi-independents or dependents when he ages or needs.

\section{Study Area: Seljuk University Elderly and Disabled Education, Care Application and Research Center, EDCRC}

About EDCRC,

- A modern wellness center, in which education, research and application coexist,

- Raising expert personnel by providing combined theoretical and applied education,

- $\quad$ Providing a wellness-production center, in addition to care and rehabilitation services,

- Enabling elderly and disabled people to re-gain their lost potentials, and develop existing ones

are some of the aims of the center (EDCRC booklet, 2013).

In this context, raising the 'planned' expert personnel in terms of elderly and disabled care, will enable this center to go beyond being the last stop of life; 
and to lead these centers to transform into a production oriented rehabilitation and living spaces.

In this context, through the project, which also includes departments of education, the center will be a working example of education-application system by means of opening related four year undergraduate programs within the university. Accordingly, the basic units that the center should include are,

- Educational institution: units that are primarily providing four-year undergraduate education, graduates of these units have the opportunity of education and application in the center,

- Elderly and disabled village: Sheltering areas that are planned to be shaped according to potentials of elderly and disabled people. For elderly and disabled people; adult care and rehabilitation areas (daily and live-in), education and rehabilitation units for disabled people aged between 3 and 25 .

- Culture complex: in which social and cultural activities take place; disabled and elderly people can actively benefit from, and get training at different interest and education level.

- Sport centers: sport areas, in which elderly and disabled people can regain their lost skills and discover new skills, with physical therapy, water (swimming pool), and music therapy.

- Workshops-production centers: units for the evaluation of free time; including production activities based on areas of interest in the center, in addition to basic needs.

- Hobby spots: recreation areas for elderly and disabled people aimed to keep them integrated with nature, in a way help them not to detach from life. With this regards, units that are used as recreation areas based on the love of nature and animal; and open areas of production spots.

- Common activity areas, worship houses: units that will enable elderly and disabled people to be altogether, containing center's meeting areas, and providing service in terms of religious needs.

In addition, the qualities that should be defined regarding the user group will be determined according to the universal design. Under the light of universal design, it is aimed to determine spatial needs and contribute to the needs of the center. 


\section{Conclusion}

Universal design guidelines needs to be incorporated into new residential construction to create more user-friendly environments for people of all ages. Using universal design principles and technological advances in building construction will create safer home environments, more user-friendly spaces, and spaces that are well adapted to everyday living for people of all abilities (Goptop and Memken 2005).

The sample area of this study, subjecting the evaluation of a series of spatial equipment design study including the arrangements for elderly and disabled people to live under the equal circumstances in the light of universal design criteria, is The Research and Rehabilitation Center for Elderly - Disabled, the design of which is not completed yet and located in Selcuk University.

The reason of investigating this research especially via universal design criteria is the investigation of the causes of the basic problems encountered by elderly and disabled individuals in daily life in the rehabilitation and research center which will be built in university land for them and gain the function of an important socialization area.

Analyzing from the perspective of Equitable Use, Flexibility in Use,Simple and Intuitive Use, Perceptible Information, Tolerance for Error, Low Physical Effort, Size and Space for Approach and Use, which are among the abovementioned universal design criteria, it is necessary to meet the needs of 'design for everyone'. In this sense, from the perspective of elderly and disabled people, the universal design principles are interpreted as the following,

- The criterion of Equitable Use should be easy to use, easy to access for different skills and perceptions. Care and sheltering needs vary according to elderly and disabled people. In this sense, it is necessary to do various spatial and equipment related adjustments in order to be easy to use. It should be easy to access in terms of sheltering options, which is referred under the title of spatial needs.

- Flexibility in Use criterion: should include wide range of options in terms of preferences and skills. Differentiation of sheltering options for elderly and disabled people, and multiplication of preferences should be solved on a platform that is convenient for perception and skills. Multiplication of options for elderly and disabled people is necessary; there should be sheltering and care options that do not detach these groups from life, and provide best service. 
- Simple and Intuitive Use criterion: the space should be transformed into platforms that integrate societies and prevent isolation; apart from the users' experience, knowledge, culture, and distinctiveness of their level of concentration.

- Perceptible Information criterion: the design should be environment-friendly and should enable the users to reveal their sensual skills. It should be in harmony with nature from the perspective of elderly and disabled people, and should minimize negative environmental factors, from which users benefit at maximum level. In this sense, the main idea is to provide an easy to access design for elderly and disabled people.

- Tolerance for Error criterion: negativities that may be caused by the accidental or unplanned structural deadlocks of the design should be minimized. In this sense, the design should be elaborated in details from programming phase to design phase, before constructing. It is necessary to determine the anthropometries and skills of elderly and disabled people, and solve spaces that will meet the needs.

- Low Physical Effort criterion: it is necessary to provide space and equipments that will require minimum tiredness, be productive and comfortable for users. In this sense, this criterion is the most important spatial and equipment related adjustment for elderly and disabled people. Coordination is number one design problem in terms of spatial arrangement and equipment both in internal/external space for those elderly and disabled people with certain disability.Within this framework, user profile should be determined carefully and usage of space should be adjusted accordingly.

- Size and Space for Approach and Use criterion: aims to shape the space according to the best spatial measure approach and guidance; and in line with users' body shape, size, and form of action. In this sense, anthropometry and form of action of elderly and disabled people should be forceful in terms of space and equipment design.

As a result of these criteria, the need program of education, care, shelter, and research center for elderly and disabled people will be shaped.

It is obvious that, the research and rehabilitation center for elderly and disabled people expected to be formed in the light of these principles should be programmed in a comprehensive way as it will be a pioneer for the buildings to be built in this area in our country. Along with this, the process cannot be completed because the details considered in programming and design phase are not applied during the construction phase. The loss of the "inclusiveness" character in the built designs is exposed with the problems lived in post occupancy process. So, a design should carry the principles mentioned above to be universal. When the universal design is considered as human focused, it is clear that the designs for specialized individuals should be done in a detailed way. As a result, this study, investigating how the 
universal design principles will affect the design in the space design for specialized elderly and disabled individuals to continue their normal lives, will enlighten the other studies in this area.

\section{References and notes:}

Anonymous (2013). YEBAV Publishing, EDCRC Booklet [YEBAM Bilgilendirme Kitapçı̆̆ı], Konya.

Akbay Esma (1998), The Examine at the Trabzon Rest Home of The Social-Cultural Structure, Economical Levels of the Old Persons According The Residence Waiting They Lived at The Past [Yaşlıların Sosyo-Kültürel Yapılarına, Ekonomik Düzeylerine Geçmişte Bulunan Ortamlara Bağlı Olarak Mekânsal Beklentilerinin Trabzon Huzur Evi Ölçeğinde İncelenmesi], Unpublished Master Thesis, Karadeniz Technical University Graduate Applied and Natural Sciences, Trabzon.

Agazade, Seymur, (2015).Testing Purchasing Power Parity Hypothesis for Azerbaijan. Khazar Journal of Humanities and Social Sciences, Volume 18, Number 3.Khazar University Press, Azerbaijan.p.48-56

Bakker Rosemary, (1997), Elderdesign: Designing and Furnishing a Home for Your Later Years, Penguin Books Press, England, ISBN: 9780140258097.

Berger, S. (2002). Universal design raises housing living standards. Retrieved January 20, 2015, from http://www.aarp.org/computers-features/Articles/a2002-07-10computers features design.html

Billig Nathan M. D., (2000). Growing Older and Wiser [Üçüncü Bahar: Yaşlılık ve Bilgelik], (trans.) Gültekin Yazgan,Evrim Publishings, İstanbul, ISBN: 9789755031057.

Boduroğlu Şenay, Seçer Kariptaş, Füsun, Sarıman Özen, Esin, (2012). Kitchen Design for Elders and Disabled people Enclosing Universal Solutions [Mutfak Tasarımında Yaşlı ve Engelli Kullanıcıları da Kapsayan Evrensel Çözümler], 18. National Ergonomy Congress, 16-18 November 2012, (400-409) Gaziantep University Department of Industrial Engineering, Gaziantep.

Brummet William J., (1994). The Essence of Home Architectural Design Considerations For Assisted Living Elderly Housing, Publications in Architecture and Veben Planning Research, Milwaukee, ISBN: 9780938744870.

Center for Universal Design. (1997). Principles of universal design. Raleigh, NY: Center for Universal Design. North Carolina State University. Retrieved December 30, 2015, from https://www.ncsu.edu/ncsu/design/cud/pubs_p/docs/poster.pdf

Gobtop, Starr M., Memken, Jean A., 2005. Housing the Elderly: Investigating Solutions to Help Seniors Age in Place, House and Society, Taylor and Francis Publication, Volume 32, Issue 1, January 2005, pages 71-84.

Karataş Birgül, (1992). Design Principles in Housing for the Elderly [Yaşlilar için Konut Opsiyonları ve Tasarlama İlkeleri], Yapı Journal, 128, (61-66), Yapı ve Endüstri Merkezi Publishings, İstanbul.

Munro Moira, (1996). Housing for the Elderly in England [İngiltere'de Yaşlılar İçin Konut], (der.) Emine M. KOMUT, Diğerlerinin Konut Sorunları (372-382), TMMOB Chamber of the Architects Publishings, Ankara. 
Regnier Victor, (1994). Assisted Living Housing For The Elderly Design Innovations From United States And Europe, Van Nostrand Reinhold Company Press, New York, ISBN: 9780471284239.

Pakdil Oya, Pakdil Fatih, (1996). Elderly care Problems, Various Services Provided for The Elderly [Yaşlıların Bakım Sorunları, Yaşlılar İçin Sağlanan Çeşitli Servisler], (der.) Emine M. Komut, Diğerlerinin Konut Sorunları (356-362). TMMOB Chamber of the Architects Publishings, Ankara.

Preiser Wolfgang F.E., Smith Korydon H., (2011). Universal Design Handbook, Second Edition, Mcgraw-Hill, USA, ISBN:9780071629232.

\section{Summary}

\section{Spatial Requirements for Elderly and Disabled People in the Frame of Universal Design}

\section{Yavuz ARAT \\ Konya Necmettin Erbakan University,Turkey}

The living areas and fulfilling all the requirements of these areas' users are very important for designers. Space design for the old and disabled users in the scope of privileged individuals is important from this point. The situation of the privileged individual mass fulfilling their basic needs like shelter, education, working and entertainment in a physically and psychologically unlimited way unlike to the other individuals is exposed as the most important design problem.

Designers must pay attention to the user desires and requirements while they design spaces. However, the desires and requirements of the changing/changed body structures of old and disabled people happen to be different from the people without any handicaps in their bodies. In this scope the stereotyped "average dimensions" used in designs are not valid in the spaces with specialized users. In other words, the arrangements without changing their living environments or using the privileged human typologies as design inputs in rebuilt spaces make it possible for old and disabled people to live without detaching from life. The basic target wanted here is with the aim of continuing a life without detaching from their families. The universal design handled in this scope developed a suggestion aiming to expose the ability to continue an equal life with all living creations. In the study the outer and inner space qualities of Konya Selcuk University Elderly and Disabled Education, Care Application and Research Center (EDCRC) project will be exemplified from the point of spatial requirements of privileged individuals.

Keywords: Housing for the Elderly and Disabled People, Universal Design, Spatial Requirements. 